\title{
ФЕДЕРАЛИЗМ И РЕГИОНАЛЬНОЕ РАЗВИТИЕ РОССИИ В «СТРАТЕГИИ 2020»
}

\begin{abstract}
Аннотация: K числу действующих федеральных документов, затрагивающих региональные аспекты стратегического развития государства, относится новейшая Концепџия долгосрочного социальноэкономического развития Российской Федерачии на период до 2020 года. В рамках данной Конщепиии содержится посвященный региональному развитию раздел, в рамках которого намечены цели и задачи территориального развития в долгосрочной перспективе, а также определены важнейшие параметры пространственного развития российской экономики и системы государственного управления.

Review: The list of effective federal documents covering regional aspects of the strategic development includes the most recent Concept of Long-Term Socio-Economic Development of the Russian Federation 2020. One section of this Concept is devoted to regional development. The section outlines long-term purposes and goals of the territorial development and defines the most important parameters of spatial development of the Russian economy and the system of public administration.
\end{abstract}

Ключевые слова: Политология, стратегия 2020, федерализм, регионализм, региональная политика, общество, государство, экономика, регионы, Россия

Keywords: political studies, Strategy 2020, federalism, regionalism, regional policy, society, state institution, economics, regions, Russia.

$\mathrm{B}$ Концепции долгосрочного социально-экономического развития Российской Федерации на период до 2020 года $^{1}$ в качестве основных целей региональной политики декларируется, с одной стороны, стремление к сбалансированному развитию регионов и межрегиональному выравниванию, а с другой - ориентация на формирование новых центров экономического роста в регионах. В частности, ставится цель значительного снижения и межрегиональной и внутрирегиональной дифференциации в уровне и качестве социального благополучия населения, а также сближение стандартов жизни между столичными регионами и периферией, крупными и малыми городами, городским и сельским населением.

К числу приоритетных относится задача создания сети территориально-производственных кластеров (или - комплексов в советской терминологии), ориентированных на высокотехнологичные производства с концентрацией таких кластеров в урбанизированных регионах. В том же ключе планируется создание территориально-производственных

\footnotetext{
${ }^{1}$ Концепция долгосрочного социально-экономического развития Российской Федерации на период до 2020 года. [Электронный ресурс] URL: ifap.ru>ofdocs/rus/rus006.pdf
}

кластеров, ориентированных на переработку сырья и производство энергии, обеспечивающих освоение новых территорий. Кроме того, в документе акцентируется внимание и на развитии крупных транспортно-логистических и производственных узлов северо-запада, юга России и Дальнего Востока. С решением этих задач связывается опережающее развитие наиболее перспективных, но в настоящее время недостаточно быстро растущих регионов. При увеличении ВВП России к 2020 г. в 2,4 раза экономический рост в Сибирском и Дальневосточном федеральных округах должен составить 2,7-2,9 раза, в Поволжье и на Урале - 3-3,3 раза. В соответствии с концептуальным замыслом, результатом этой преобразовательной деятельности государства должна стать не только более разнообразная (многополярная), но при этом и более сбалансированная конфигурация пространственного развития страны, не привязанная жестко к сложившимся энерго-сырьевым и финансовым центрам.

Однако с учетом колоссальной социально-экономической диспропорции регионального развития цели снижения межрегиональной дифференциации приобретают, по сути дела, декларативный характер. В условиях доминирования очагового типа экономического роста, который предполага- 


\section{Политика и общество $10(106) \cdot 2013$}

ется в стратегии, региональное неравенство в социально-экономической сфере только усиливается. Межрегиональная дифференциация по объему ВРП на душу населения с 2000 г. выросла с 26 раз до 45. Таким образом, Россия все в большей степени разделяется на модернизирующиеся регионы, где концентрируются возможности экономического роста, и депрессивные регионы.

Рассматриваемая концепция затрагивает вопрос о первичности общегосударственной стратегии и стратегий регионов, каждая из которых ориентирована на достижение разных целей посредством использования разных механизмов. К тому же, с учетом того, что общенациональная стратегия предполагает реализацию интересов федерального центра, а стратегия региона опирается на региональные интересы, постановка такого вопроса весьма противоречива. Более важным является вопрос о соотношении подобного рода стратегий: данные стратегии должны быть взаимодополняющими, направленными на согласование интересов как федерального центра, так и регионов. Вопрос приоритетности одной стратегии по отношению к другой акцентирует внимание на конкуренции федерального центра и регионов, что провоцирует обострение отношений по вертикали. Таким образом, приоритеты регионального развития в «Стратегии 2020» сводятся к сокращению межрегиональной дифференциации посредством использования механизмов территориального планирования.

Изменение и совершенствование механизмов региональной политики также отражает цикличность процессов централизации/децентрализации. Так в 1990-е гг., в Российской Федерации федеральная региональная политика проявлялась чаще всего в форме несистематизированных краткосрочных действий федерального правительства в соответствии с целями региональных и особенно республиканских властей и элит. Государственная политика была направлена, прежде всего, на решение краткосрочных задач и ликвидацию критических, а то и просто чрезвычайных ситуаций, и лишь затем на попытку борьбы с нарастающими территориальными диспропорциями. При предоставлении территориальным единицам льгот большую роль играли субъективные факторы, обусловленные административным усилением регионального уровня ${ }^{2}$. Препятстви-

\footnotetext{
2 Лексин В.Н. Федеративная Россия и её региональная политика. - М.: ИНФРА - М, 2008. - 352 с.
}

ем для повышения государственного регулирования развития территорий являлась также и ведомственная раздробленность в выработке направлений и реализации региональной политики, несогласованность действий федеральных, региональных и органов местного самоуправления. Предпринятая в период 1990-х гг. попытка приспособить привычные административные методы к управлению к условиям рыночной экономики привела к провалу реконструкции системы регионального развития ${ }^{3}$.

С переходом к новой системе территориально-политической и экономической организации на смену централизованно-плановому распределению хозяйственного потенциала по территории страны пришел стихийный процесс стягивания производства и социально-экономической активности в целом в наиболее жизнеспособные ареалы, что стало основной причиной резкого увеличения социально-экономических диспропорций ${ }^{4}$. В настоящий момент основной целью региональной политики является сглаживание социально-экономической асимметрии.

В начале 2000-х гг. при постепенном усилении центральной власти наблюдается более комплексный подход при решении региональных проблем. В частности, решается проблема статусной и правовой асимметрии, региональное законодательство приводится в соответствие с федеральным. Посредством проведения реформы федеральных округов усиливается элемент федерального присутствия на региональном уровне за счет расширения полномочий полпредов и реорганизации силовых структур по окружному принципу. Таким образом, структура взаимодействия между центром и регионами постепенно приводится к единому формату. С усилением финансовых и административных возможностей федерального центра усиливается роль бюджетно-налоговых и программно-целевых механизмов в осуществлении региональной политики. Использование таких механизмов свидетельствует о доминировании селективного подхода при осуществлении региональной политики.

В идеале государственная региональная политика должна содержать в себе компоненты и селективности, и общесистемности. Обращаясь к практике

\footnotetext{
3 Туровский Р.Ф. Центр и регионы: проблемы политических отношений. М., 2007.

${ }^{4}$ Швецов А.Н. Совершенствование региональной политики: концепции и практика. Изд. 2-е, М., 2011
} 
использования механизмов регионального развития можно констатировать, что при сложившейся высокой степени централизации ресурсов и полномочий совокупность реальных действий федеральных органов власти, которая по своему предметному содержанию может квалифицироваться в качестве региональной политики, неизбежно приобретает в большей степени селективно-поддерживающий, чем общесистемно-институциональный характер. Однако проведение такого рода региональной политики на практике оказывается неэффективным по причине того, что слишком часто решения, принимаемые в отношении поддержки конкретных регионов, определяются не столько социально-экономическими соображениями, сколько результатами политического лоббирования интересов региональных элит. Кроме того, крупные субсидии центра неминуемо порождают иждивенческие настроения региональных властей, что приводит к снижению стимулов регионального развития.

В условиях менее централизованной системы организации регионального развития пропорция между компонентами региональной политики, скорее всего, изменится. Получив больше средств и полномочий, региональные власти смогут значительно расширить свои возможности самостоятельного (то есть без участия федерального центра) решения проблем регионального развития, в то время как федеральные власти смогут сосредоточится на вопросах создания необходимых для этого условий и предпосылок. Это приведет к снижению роли селективной составляющей региональной политики и возрастание значения ее общесистемного компонента.

При переходе к более децентрализованной системе сам собой отпадает вопрос о том, каким регионам необходима федеральная поддержка. Следует отметить, что принятая в 2005 году в Минрегионразвития России концепция регионального развития предусматривает переход от политики государственной поддержки депрессивных регионов к поддержке региональных «точек роста» - наиболее успешно развивающихся регионов, которым отводится роль «локомотивов» регионального развития, что в перспективе приведет к усилению горизонтальных связей и позволит развивать депрессивные регионы. Безусловно, подобный вариант в наибольшей степени выгоден регионам-лидерам, поскольку предоставляет им возможность преодолеть общесистемные ограни- чения (прежде всего, ресурсные), которые накладывает на процессы регионального развития высокоцентрализованная система государственного регулирования. Таким образом, в случае децентрализации ресурсов и полномочий регионы-лидеры выиграют намного больше, чем в условиях получения ими централизованной поддержки. При прочих равных условиях самостоятельное распоряжение своими собственными потенциалами позволит этим регионам обеспечить свой рост без федеральной поддержки. Но при этом отсталым регионам, не располагающим достаточным потенциалом развития, не обойтись без государственной поддержки. Таким образом, в силу имеющейся дифференциации регионального развития наиболее целесообразным вариантом при выработке стратегии региональной политики является сочетание обоих компонентов регулирования регионального развития: как общесистемного, так и селективного. В то же время нестабильность политической системы и сохраняющаяся персонифицированность регулирования регионального развития создает проблематичность реализации стратегических инициатив.

\section{Библиография:}

1. Концепция долгосрочного социально-экономического развития Российской Федерации на период до 2020 года. [Электронный ресурс] URL: ifap. ru>ofdocs/rus/rus006.pdf

2. Лексин В.Н. Федеративная Россия и её региональная политика. - М.: ИНФРА - М, 2008. - 352 с.

3. Швецов А.Н. Совершенствование региональной политики: концепции и практика. Изд. 2-е, М., 2011

4. Туровский Р.Ф. Центр и регионы: проблемы политических отношений. М., 2007.

\section{References (transliteration):}

1. Leksin V.N. Federativnaya Rossiya i ee regional'naya politika. - M.: INFRA - M, 2008. - 352 s.

2. Shvetsov A.N. Sovershenstvovanie regional'noi politiki: kontseptsii i praktika. Izd. 2-e, M., 2011

3. Turovskii R.F. Tsentr i regiony: problemy politicheskikh otnoshenii. M., 2007. 